Tropical Journal of Pharmaceutical Research August 2012; 11 (4): 561-568

(C) Pharmacotherapy Group, Faculty of Pharmacy, University of Benin Benin City, 300001 Nigeria.

All rights reserved.

Available online at http://www.tjpr.org

Research Article

http://dx.doi.org/10.4314/tjpr.v11i4.6

\title{
Formulation and Characterization of Sustained Release Floating Microballoons of Metformin Hydrochloride
}

\author{
Akash Yadav* and Dinesh Kumar Jain \\ ${ }^{1}$ Department of Pharmaceutics, College of Pharmacy, Indore Professional Studies (IPS) Academy, Knowledge \\ Village, Agra-Bombay Road, Rajendra Nagar, Indore (Madhya Pradesh)-452012, India.
}

\begin{abstract}
Purpose: To formulate sustained release gastroretentive microballoons of metformin hydrochloride with the objective of improving its bioavailability.

Methods: Microballoons of metformin hydrochloride were formulated by solvent evaporation and diffusion method using varying mixtures of hydroxypropyl methylcellulose (HPMC) and ethyl cellulose (EC) polymers. The balloons were characterized for particle size, surface morphology, incorporation efficiency, floating behavior and in vitro drug release.

Results: The mean particle size of the formulated microballoons was in the range of $34.2 \pm 4.7$ to $95.7 \pm$ $2.2 \mu \mathrm{m}$. Incorporation efficiencies of over $83.8 \pm 0.9 \%$ were achieved for the optimized formulations. Most of the formulations were buoyant with maximum buoyancy of $81.4 \pm 2.0 \%$ for $>12 \mathrm{~h}$, showing good floating behavior of microballoons. Release kinetic data showed best fit to the Higuchi model, indicating that diffusion was the predominant mechanism of drug release.

Conclusion: Microballoons is a potential suitable delivery system for sustained release of metformin hydrochloride with improved bioavailability when compared with conventional dosage forms of the drug.
\end{abstract}

Keywords: Gastroretentive drug delivery system (GDDS), Solvent evaporation and diffusion method, Higuchi, Microballoons, Metformin hydrochloride 


\section{INTRODUCTION}

Oral administration is the most convenient and preferred route of drug delivery to the systemic circulation. Many attempts have been made to develop sustained release preparations with extended clinical effects and reduced dosing frequency. In order to develop oral drug delivery systems, it is necessary to optimize both the release rate of the drug and the residence time of the system within the gastrointestinal tract.

Various approaches have been used to retain dosage forms in the stomach [1-3] in order to increase gastric residence time (GRT). These include those that utilize floating [4-7], high density [3], mucoadhesive [8], magnetic [9], unfoldable, extendible or swellable [10] and superporous hydrogel [11] systems. Both natural and synthetic polymers have been used to prepare floating microspheres. Preparation of hollow microspheres or microballoons of ibuprofen by the emulsionsolvent diffusion method using acrylic polymers has been reported [12]. These systems allow prolonged residence time of dosage forms in the stomach and achievement of constant plasma levels; however, it is necessary to analyze gastrointestinal transit behavior in humans to confirm the suitability of the concept as far as final design is concerned [13].

Metformin was used as a model drug. It is an anti-hyperglycemic agent, which improves glucose tolerance in type II diabetes [14]. It is poorly absorbed from the lower gastrointestinal tract (GIT) and has a short elimination half life $(1.5-1.6 \mathrm{~h})$. The objective of the present study was to develop floating microballoons of metformin in order to achieve extended retention in the upper GIT, which may result in enhanced absorption and thereby improved bioavailability.

\section{EXPERIMENTAL}

\section{Materials}

Metformin hydrochloride was received as a gift from Sohan Pharmaceuticals Ltd, Pune, India. Hydroxypropyl methylcellulose, ethyl cellulose and Tween 80 were purchased from Loba Chem Pvt Ltd, Mumbai, India. Ethanol was supplied by S.D. Fine Chem Ltd, Mumbai, India. Dichloromethane was purchased from CDH Ltd, New Delhi, India. All chemicals/reagents used were of analytical grade.

\section{Methods}

\section{Preparation of microballoons}

Microballoons were prepared by solvent evaporation technique [15]. Metformin hydrochloride $(100 \mathrm{mg}$ ) and HPMC and EC were used in different ratios i.e. 1:1, 1:2, 1:4, $1: 6,2: 1,4: 1 \& 6: 1$. The total weight of HPMC and EC per $100 \mathrm{mg}$ of metformin were kept constant at $200 \mathrm{mg}$. The polymers were dissolved in a mixture of alcohol and dichloromethane (in varying ratios, i.e., 1:1, $2: 1,1: 2)$. The total amount of solvent mixture was kept constant at $100 \mathrm{ml}$ and the procedure was carried out at room temperature. The resulting solution was poured into $250 \mathrm{ml}$ of distilled water containing $0.01 \% \mathrm{v} / \mathrm{v}$ Tween 80 , maintained at different temperatures (i.e., 10, 20, 30 and $\left.40{ }^{0} \mathrm{C}\right)$, and then stirred at varying agitation speed (250 - $1000 \mathrm{rpm}$ ) for $20 \mathrm{~min}$ to allow the volatile solvent to evaporate. The microballoons formed were filtered, washed with distilled water and dried.

\section{Size and shape of microballoons}

The size of microballoons was determined using a light microscope (BEM-21, Besto Microscope, India) fitted with an ocular and stage micrometer. Scanning electron microscopy (SEM, Philips-XL-20, Netherlands) was performed to characterize the surface morphology of the formed 
microballoons. Microballoons were mounted directly onto the sample stub and coated with gold film $(200 \mathrm{~nm})$ under reduced pressure $(0.133 \mathrm{~Pa})$, prior to measurement.

\section{Drug loading (DL), incorporation efficiency (IE), and yield}

In order to determine incorporation efficiency, microballoons $(30 \mathrm{mg})$ were thoroughly triturated and suspended in $20 \mathrm{ml}$ of alcohol, diluted (10 times) with $0.1 \mathrm{M} \mathrm{HCl}(\mathrm{pH} 1.2)$ and filtered to remove shell fragments. Metformin hydrochloride content was analyzed spectrophotometrically (Shimadzu 1800, Japan) at $233 \mathrm{~nm}$ in order to determine drug loading (DL) using Eq 1. To calculate yield, the prepared microballoons were collected and weighed. Yield and incorporation efficiency (IE) were calculated as in Eqs 2 and 3.

DL $(\%)=\left(M_{1} / M_{2}\right) 100$

where $M_{1}$ is the amount of drug in the microballoons and $M_{2}$ is the total weight of the recovered microballoons

Yield $(\%)=\left(\mathrm{W}_{1} / \mathrm{W}_{2}\right) 100$

where $\mathrm{W}_{1}$ is the total weight of floating microballoons and $W_{2}$ is the total weight of all non-volatile components

IE $(\%)=(C 1 / C 2) 100$

where $\mathrm{C}_{1}$ is the actual (computed) drug content of the microballoons and $\mathrm{C}_{2}$ is the theoretical drug content.

\section{In vitro drug release}

A USP paddle apparatus (Lab India, Mumbai, India), containing $900 \mathrm{ml}$ of $0.1 \mathrm{M} \mathrm{HCl}(\mathrm{pH}$ 1.2) maintained at $37 \pm 0.5{ }^{\circ} \mathrm{C}$ and with agitation speed set at $100 \mathrm{rpm}$,was used to study the in vitro drug release of the microballoons [16]. Samples $(5 \mathrm{ml})$ were withdrawn at intervals of $2 \mathrm{~h}$, filtered through $0.25 \mu \mathrm{m}$ membrane filter (Millipore) and analyzed spectrophotometrically at $233 \mathrm{~nm}$. The volume of the dissolution medium was replenished with the same amount of fresh dissolution fluid each time a sample was withdrawn to maintain sink conditions.

\section{Release kinetic analysis}

Different kinetic equations (zero-order, first order and Higuchi's equation) were applied to the release data of the optimized batches to determine the release mechanism of the microballoons [17-19]. Drug released at specified time periods was plotted as percent drug release versus time curve (zero order kinetics). Similarly, log of \% of unreleased drug was plotted versus time curve (first order kinetics) and percent of drug release was plotted versus square root of time (Higuchi model).

\section{Buoyancy test}

Microballoons $(0.3 \mathrm{~g})$ were spread over the surface of $900 \mathrm{ml}$ of simulated gastric fluid $(\mathrm{pH} 1.2)$ in a USP type II dissolution apparatus (Lab India, Mumbai, India). The medium was agitated by the paddle rotating at $75 \mathrm{rpm}$ for $12 \mathrm{~h}$. The floating and the settled portions of microballoons were recovered separately, dried and weighed. Buoyancy was calculated as the ratio of the mass of the microballoons that remained floating and the total mass of the microballoons.

\section{Statistical analysis}

Statistical analysis was performed with the Graph Pad Instat 3 software (Graph Pad Software Inc, San Diego, CA). All the tests were run in triplicate $(n=3)$. Quantitative data were expressed as mean \pm standard deviation (SD) and all the data were statistically analyzed by one way analysis of variance (ANOVA) with post-test (Dunnett multiple comparison test). Statistically significant difference between formulations was set at $p \leq 0.05$.

\section{RESULTS}

\section{Size and shape of microballoons}

The mean particle size of the formulations ( $P 1$ to $P 16)$ was in the range of $34.2 \pm 4.65$ to 
$95.7 \pm 2.2 \mu \mathrm{m}$ (Table 1). The mean particle size and wall thickness of microballoons increased with increase in the polymer concentration. The results shows that the larger the particle size, the longer the floating time. The results also show that at higher temperatures, the shell of the microballoons was very thin and some of them were broken (formulation P16) which might be due to the faster diffusion of alcohol in the droplets into aqueous phase and immediate evaporation of dichloromethane following its introduction into the medium. Scanning electron microscopy (SEM) revealed pores on the microballoons (Fig 1).

\section{Yield and drug loading (DL)}

The yield of microballoons was $>72 \%$ for all the formulations while drug loading was in the range of $105.4 \pm 1.5$ to $125.5 \pm 1.6 \mu \mathrm{g} / \mathrm{mg}$ (Table 1).

Table 1: Effect of various processing parameters on the particle size, drug loading, incorporation efficiency (IE), yield and buoyancy of microballoons

\begin{tabular}{|c|c|c|c|c|c|c|c|c|}
\hline \multirow{2}{*}{$\begin{array}{l}\text { Formulation } \\
\text { Code }\end{array}$} & \multicolumn{4}{|c|}{ Process conditions } & \multirow{2}{*}{$\begin{array}{l}\text { Yield } \\
(\%)\end{array}$} & \multirow{2}{*}{$\begin{array}{l}\text { Drug } \\
\text { Loading } \\
(\mu \mathrm{g} / \mathrm{mg})\end{array}$} & \multirow[t]{2}{*}{ IE (\%) } & \multirow{2}{*}{$\begin{array}{l}\text { Percentage } \\
\text { buoyancy }\end{array}$} \\
\hline & $\begin{array}{l}\text { Polymer } \\
\text { ratio } \\
\text { HPMC:EC }\end{array}$ & $\begin{array}{l}\text { Solvent } \\
\text { ratio }\end{array}$ & $\begin{array}{l}\text { Temperature } \\
\left({ }^{0} \mathrm{C}\right)\end{array}$ & $\begin{array}{l}\text { Mean } \\
\text { particle } \\
\text { size }(\mu \mathrm{m})\end{array}$ & & & & \\
\hline P1 & $1: 1$ & $1: 1$ & $30^{\circ} \mathrm{C}$ & $54.2 \pm 2.7$ & $74.2 \pm 1.8$ & $116.0 \pm 1.2$ & $78.2 \pm 1.1$ & $73.6 \pm 2.0$ \\
\hline P2 & $1: 2$ & $1: 1$ & $30^{\circ} \mathrm{C}$ & $73.8 \pm 3.1$ & $76.3 \pm 1.9$ & $118.7 \pm 1.6$ & $82.3 \pm 1.1$ & $74.3 \pm 2.0$ \\
\hline P3 & $1: 4$ & $1: 1$ & $30^{\circ} \mathrm{C}$ & $88.2 \pm 4.0$ & $78.2 \pm 1.6$ & $117.6 \pm 1.8$ & $83.6 \pm 0.8$ & $76.6 \pm 2.2$ \\
\hline P4 & $1: 6$ & $1: 1$ & $30^{\circ} \mathrm{C}$ & $95.7 \pm 2.1$ & $76.1 \pm 1.3$ & $121.1 \pm 1.5$ & $83.9 \pm 0.9$ & $78.1 \pm 1.9$ \\
\hline P5 & $2: 1$ & $1: 1$ & $30^{\circ} \mathrm{C}$ & $34.1 \pm 4.7$ & $75.2 \pm 1.3$ & $113.5 \pm 1.9$ & $77.6 \pm 0.6$ & $73.8 \pm 2.3$ \\
\hline P6 & $4: 1$ & $1: 1$ & $30^{\circ} \mathrm{C}$ & $58.8 \pm 4.0$ & $73.6 \pm 1.7$ & $115.3 \pm 1.2$ & $77.2 \pm 1.2$ & $78.6 \pm 2.8$ \\
\hline P7 & $6: 1$ & $1: 1$ & $30^{\circ} \mathrm{C}$ & $73.6 \pm 4.0$ & $72.5 \pm 1.7$ & $125.5 \pm 1.6$ & $82.7 \pm 1.0$ & $81.4 \pm 2.0$ \\
\hline P9 & $1: 2$ & $1: 1$ & $40^{\circ} \mathrm{C}$ & $71.0 \pm 3.8$ & $76.3 \pm 1.1$ & $114.0 \pm 1.5$ & $79.1 \pm 1.6$ & $76.3 \pm 1.8$ \\
\hline P10 & $1: 2$ & $1: 1$ & $10^{\circ} \mathrm{C}$ & $56.1 \pm 2.6$ & $72.3 \pm 1.9$ & $114.9 \pm 1.4$ & $75.6 \pm 1.3$ & $74.2 \pm 2.1$ \\
\hline P11 & $1: 2$ & $1: 1$ & $20^{\circ} \mathrm{C}$ & $73.8 \pm 3.1$ & $76.3 \pm 1.9$ & $118.7 \pm 1.8$ & $82.3 \pm 1.1$ & $74.3 \pm 2.0$ \\
\hline P12 & $1: 2$ & $2: 1$ & $30^{\circ} \mathrm{C}$ & $67.4 \pm 3.1$ & $78.6 \pm 1.5$ & $105.4 \pm 1.5$ & $75.3 \pm 0.9$ & $71.2 \pm 2.3$ \\
\hline P13 & $1: 2$ & $1: 1$ & $40^{\circ} \mathrm{C}$ & $78.7 \pm 3.6$ & $76.9 \pm 1.5$ & $111.9 \pm 1.7$ & $78.2 \pm 0.7$ & $72.8 \pm 3.1$ \\
\hline P15 & $1: 2$ & $1: 2$ & $30^{\circ} \mathrm{C}$ & $71.9 \pm 3.4$ & $78.4 \pm 1.9$ & $110.4 \pm 1.8$ & $78.6 \pm 1.0$ & $74.3 \pm 1.7$ \\
\hline P16 & $1: 2$ & $1: 2$ & $20^{\circ} \mathrm{C}$ & $62.0 \pm 3.8$ & $74.2 \pm 1.0$ & $108.6 \pm 1.2$ & $73.2 \pm 1.0$ & $76.2 \pm 2.1$ \\
\hline
\end{tabular}

${ }^{*}$ Formulations were prepared at varying agitation speed (250, 500, 750 and $\left.1000 \mathrm{rpm}\right)$

† Formulations were prepared at varying temperatures i.e. $10^{\circ} \mathrm{C}, 20^{\circ} \mathrm{C}, 30^{\circ} \mathrm{C} \& 40^{\circ} \mathrm{C}$

$\ddagger$ Polymer ratio (HPMC: EC) i.e. 1:1, 1:2, 1:4, 1:6, 2:1, 4:1 \& 6:1.

Table 2: Release kinetic data for metformin hydrochloride microballoons

\begin{tabular}{lllllll}
\hline $\begin{array}{l}\text { Formulation } \\
\text { Code }\end{array}$ & $\begin{array}{l}\text { Zero order* } \\
\mathbf{K}_{\mathbf{0}}\end{array}$ & $\mathbf{r}^{\mathbf{2}}$ & $\begin{array}{l}\text { First order } \\
\mathbf{K}_{\mathbf{1}}\end{array}$ & $\mathbf{r}^{\mathbf{2}}$ & Higuchi $^{*}$ \\
\hline $\mathrm{\mathbf {K } _ { \mathbf { H } }}$ & $\mathbf{r}^{\mathbf{2}}$ \\
$\mathrm{P}-3^{\#}$ & 0.1215 & 0.909 & 10.517 & 0.983 & 0.0347 & 0.909 \\
$\mathrm{P}-9^{\#}$ & 0.1597 & 0.921 & 23.008 & 0.954 & 0.0447 & 0.966 \\
$\mathrm{P}-12^{\#}$ & 0.1242 & 0.900 & 11.517 & 0.983 & 0.0357 & 0.991 \\
$\mathrm{P}-15^{\#}$ & 0.1211 & 0.883 & 10.312 & 0.964 & 0.0351 & 0.981 \\
\hline
\end{tabular}

${ }^{*} \mathrm{~K}_{0}\left(\mathrm{~h}^{-1}\right), \mathrm{K}_{1}\left(\mathrm{~h}^{-1}\right)$ and $\mathrm{K}_{\mathrm{H}}\left(\mathrm{h}^{-1 / 2}\right)$ are release rate constants for Zero, First and Higuchi

kinetic treatment respectively.

\#P-2: Polymer ratio (HPMC:EC) 1:2, Solvent ratio (E:DCM): 1:1, Temperature: $30^{\circ} \mathrm{C} \&$ Agitation speed: $250 \mathrm{rpm}$

\#P-3: Polymer ratio (HPMC:EC): 1:4, Solvent ratio (E:DCM): 1:1, Temperature: $30^{\circ} \mathrm{C} \&$ Agitation speed: $250 \mathrm{rpm}$ \#P-9: Polymer ratio (HPMC:EC): $1: 2$, Solvent ratio (E:DCM): $1: 1$, Temperature: $40^{\circ} \mathrm{C}$ \& Agitation speed: $500 \mathrm{rpm}$ \#P-12: Polymer ratio: (HPMC:EC) 1:2, Solvent ratio (E:DCM): 2:1, Temperature: $30^{\circ} \mathrm{C}$ \& Agitation speed: $750 \mathrm{rpm}$ \#P-15: Polymer ratio: (HPMC:EC) 1:2, Solvent ratio (E:DCM): 2:1, Temperature: $30^{\circ} \mathrm{C} \&$ Agitation speed: $1000 \mathrm{rpm}$ 

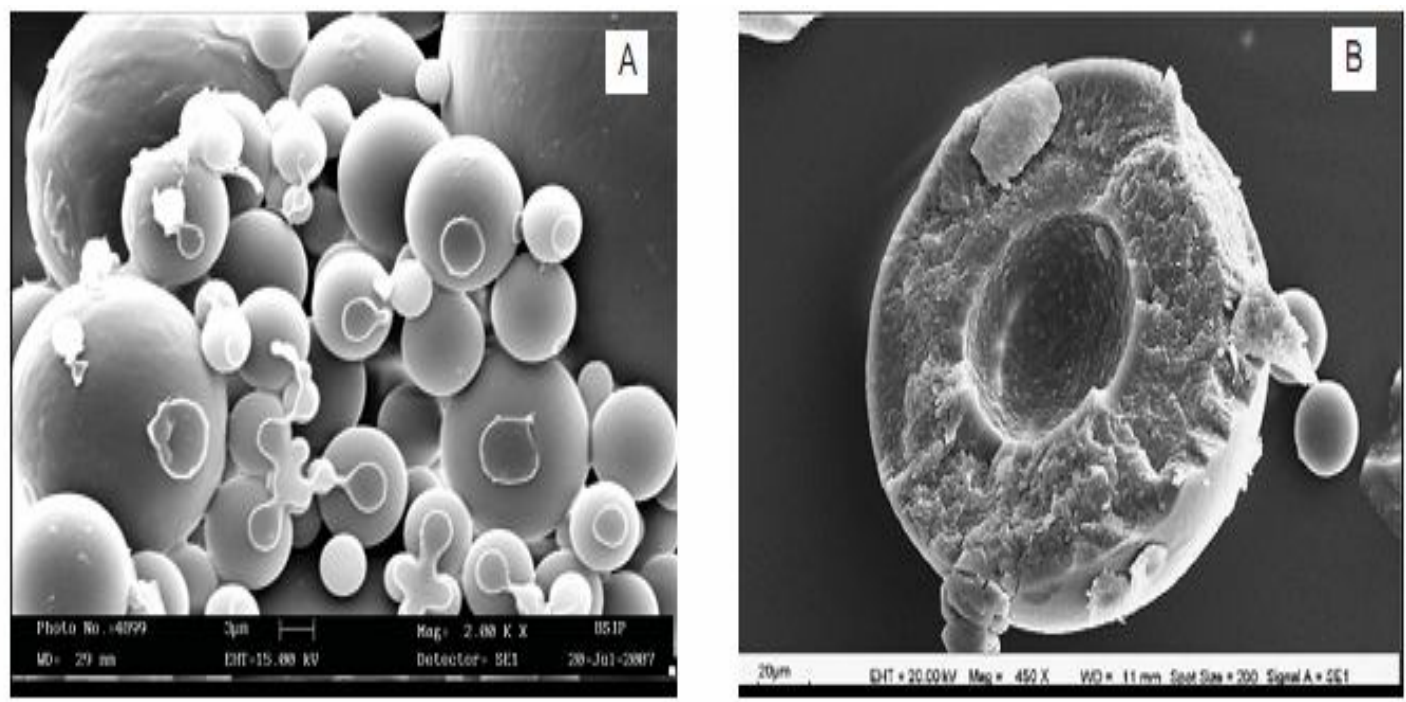

Figure 1: Scanning electron micrograph (SEM) of microballoons: (A) outer surface; (B) inner surface of a cross-section

\section{Incorporation efficiency (IE)}

Incorporation efficiency was in the range of $73.2 \pm 1.0$ to $83.9 \pm 0.9$ while more than 71 $\%$ microballoons remained floating at the end of $12 \mathrm{~h}$. (Table 1).

\section{In vitro drug release}

The results in Fig. 2 indicate that the proportion of polymers in the formulation was the key factor governing drug release from the microballoons. As the polymer concentration increased, drug release from the microballoons decrease. The formulation containing a higher proportion of EC in the polymer blend exhibited lower drug release than those with HPMC in a higher proportion. Another process variable that influenced drug release was agitation speed. At higher agitation speed during preparation, smaller microballoons were formed, resulting in higher drug release. Solvent composition did not produce a significant effect $(p<0.05)$ on drug release. Microballoons prepared at higher temperature $\left(40{ }^{\circ} \mathrm{C}\right)$ were slightly larger in size due to the thin shell of the

microballoons (Fig 3). Cumulative drug release by the microballoons after $12 \mathrm{~h}$ was

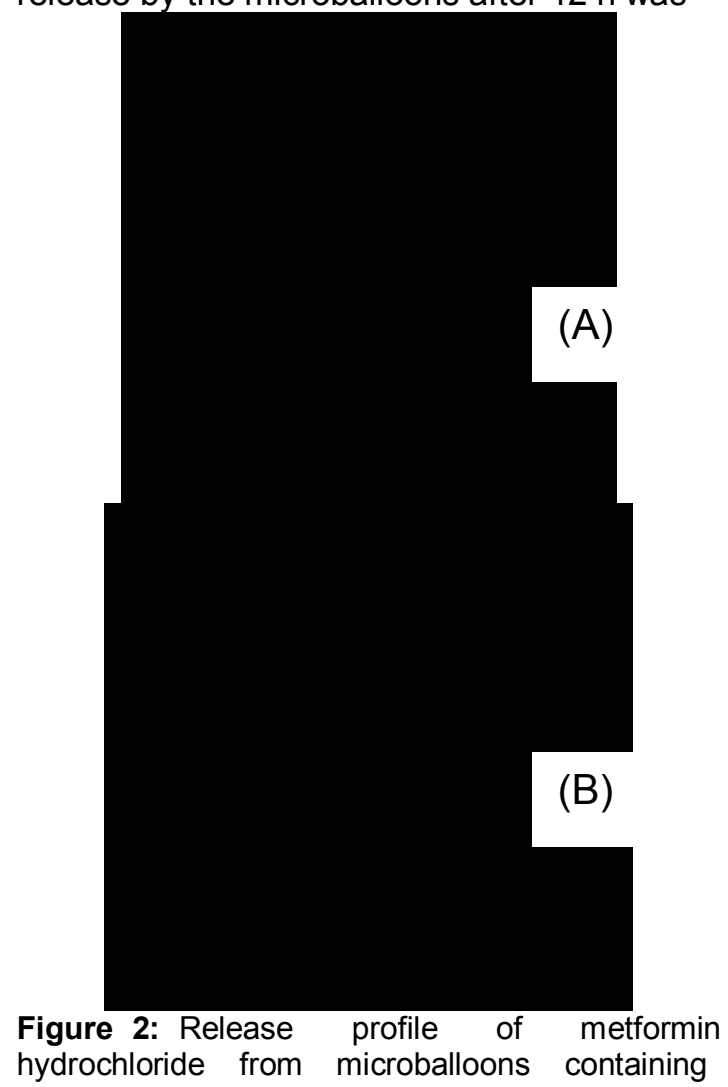


(A) Varying concentrations of EC $(\diamond, \mathrm{P} 1 ; \mathbf{\square}, \mathrm{P} 2 ; \Delta$, $\mathrm{P} 3 ; \mathrm{X}, \mathrm{P} 4)$ and (B) Varying concentrations of $\operatorname{HPMC}(\diamond, \mathrm{P} 5 ; \mathbf{\bullet}, \mathrm{P} 6 ; \Delta, \mathrm{P} 7)$

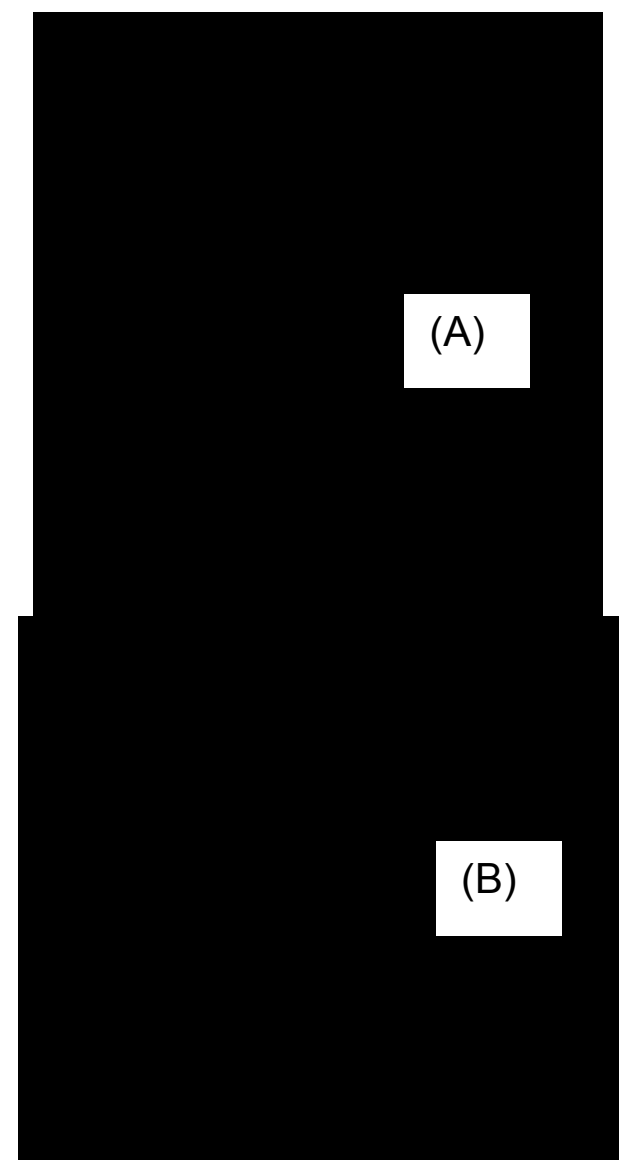

Figure 3: Release profile of metformin hydrochloride from microballoons $(A)$ prepared at different agitation speeds ( $\diamond, \mathrm{P} 9 ; \mathbf{\square}, \mathrm{P} 10)$ and prepared with varying solvent compositions $(\Delta$, P11, x, P12; O, P13); and (B) prepared at different temperatures $(\diamond, \mathrm{P} 15 ; \mathbf{\square}, \mathrm{P} 16)$

in the range of $60.5 \pm 1.2$ to $96.4 \pm 1.1 \%$. The effects of both solvent composition and temperature on in vitro release of metformin hydrochloride were insignificant $(p<0.05)$. The release kinetic data obtained fitted most to the Higuchi model (Table 2), thus indicating that diffusion was the predominant mechanism of drug release. Up to $80 \%$ of the microballoons remained floating for longer than $12 \mathrm{~h}$, thereby ensuring the release of the drug into the simulated gastric fluid in a sustained manner.

\section{DISCUSSION}

Ethanol, is a good solvent for EC and HPMC and therefore would preferentially diffuse out of disperse droplets (organic phase) into the aqueous phase used in this study; this resulted in the polymer blend instantly solidifying as a thin film at the interface between the aqueous and the organic phases. The yield of microballoons is a function of diffusion of solvents in the organic phase into aqueous phase. It has been reported that when the diffusion rate of solvent out of emulsion droplet is too slow, microspheres coalesce together. Conversely, when the diffusion of solvent is too fast, the solvent may diffuse into the aqueous phase before stable emulsion droplets are developed, causing aggregation of embryonic microsphere droplets [20]. The results of this study indicate that the formation of microballoons is a function of process variables such as polymer concentration, solvent composition, rate of agitation and temperature. The temperature of the dispersing medium was an important factor in the formation of microballoons because it controlled the rate of evaporation of the solvent. The optimum temperature for the formation of microballoons with good floating properties was room temperature (formulation P15).

The mean particle size and wall thickness of the microballoons increased with increase in polymer concentration. This may be attributed to increased viscosity of the medium at higher polymer concentration resulting in enhanced interfacial tension. Shearing efficiency diminishes also at higher viscosities, resulting in the formation of larger particles.

When the rotation speed of propeller was fast $(1000 \mathrm{rpm})$, the average particle size decreased and their morphological 
characteristics were maintained. At low rotation speed (250 rpm), the shear force was not sufficient to form stable emulsion droplets, and hence larger droplets were formed which subsequently aggregated. Thus, the optimum rotation speed for the formulations made in this study is medium, i.e., $500 \mathrm{rpm}$, based on the mean particle size and incorporation efficiency of formulation P9.

Solvent composition was found to be a vital factor in the formulation process governing the yield and particle size of microballoons. As the amount of dichloromethane increased, the average particle size of microballoons also increased. Since alcohol preferentially diffused out of the emulsion droplets, dichloromethane became the major constituent of the internal organic phase. The polymer, not being soluble at the interface between dichloromethane and aqueous phase, progressively solidified around dichloromethane-rich emulsion droplets and the volume of dichloromethane within the droplets became the size determining factor. The content of dichloromethane also affected the morphology of microballoons and the best results were obtained at alcohol : dichloromethane ratio of 2:1 (formulation P12).

Microballoons formulated with the polymer blend in which HPMC constituted the higher proportion (formulations P5, P6 and P7) were smaller in size than microballoons in which EC formed the higher proportion. The solvent diffusion and evaporation method used produced spherical microballoons with smooth outer surface and hollow core. Incorporation efficiency of formulated microballoons was a function of process variables as well as the physicochemical properties of drug. It was observed that variation in polymer concentration influenced incorporation efficiency. This is because the increase in viscosity at higher polymer concentrations restricted the movement of drug from the polymer matrix into the aqueous phase. Drug solubility in the organic solvents also affected incorporation efficiency. The drug is hydrophilic, and therefore, it would leach optimally into the aqueous phase. However, increase in polymer concentration had no impact on the yield of microballoons.

In the present study, the polymer content of the formulation was the key factor governing drug release from the microballoons. It seems that as the polymer content increased, there was an increased in the diffusional path length of the drug, thus decreasing the overall drug release rate from the polymer matrix.. Also, since higher rotation speed yielded smaller microballoons in which in turn increased drug release, it is clear why higher agitation resulted in microballoons with faster drug release. The effects of both solvent composition and temperature on in vitro release of metformin hydrochloride were, however, insignificant $(p<0.05)$. The release kinetic data obtained fitted most to the Higuchi model, thus indicating that diffusion was the predominant mechanism of drug release. As high as $>80 \%$ of the microballoons remained floating for longer than $12 \mathrm{~h}$, thereby ensuring the release of the drug into the simulated gastric fluid in a sustained manner.

\section{CONCLUSION}

Metformin hydrochloride microballoons with good floatation sustained release characteristics in simulated gastric fluid in vitro has been successfully developed using the solvent evaporation and diffusion method. In vivo studies are, however, required to establish the suitability of the formulation method used.

\section{ACKNOWLEDGEMENT}

The authors are very grateful to College of Pharmacy, IPS Academy, Indore, for providing all the necessary facilities for carrying out this study. The authors also wish to thank Dr Praveen Malviya, Indian Institute 
of Technology (IIT), New Delhi, India, for assistance with SEM facilities.

\section{REFERENCES}

1. Moes AJ. Gastroretentive dosage forms. Crit. Rev. Ther. Drug. Syst. 1993; 10: 143-195.

2. Deshpande AA, Rhodes CT, Shah NH, Malick AW. Controlled release drug delivery systems for prolonged gastric residence: an overview. Drug Dev. Ind. Pharm. 1996; 22: 531-539.

3. Hwang SJ, Park H, Park K. Gastric retentive drug delivery systems. Crit. Rev. Ther. Drug Carr. Syst. 1998; 15: 243-284.

4. Yuasa H, Takashima Y, Kanaya Y. Studies on the development of intragastric floating and sustained release preparation: I. Application of calcium silicate as a floating carrier. Chem. Pharm. Bull. 1996; 44: 1361-1366.

5. Rouge N, Cale ET, Doelker E, Buri P. Buoyancy and drug release patterns of floating minitablets containing piretanide and atenolol as model drugs. Pharm. Dev. Technol. 1998; 3: 73-84.

6. Lee JH, Park TG, Choi HK. Development of oral drug delivery system using floating microspheres. J. Microencapsul. 1999; 16: 715-729.

7. Tripathi G, Singh S. Formulation and In vitro evaluation of $\mathrm{pH}$ sensitive oil entrapped polymeric blended gellan gum buoyant beads of clarithromycin, DARU. 2010; 18: 247-253.

8. Akiyama $Y$, Nagahara $N$, Kashihara $T$, Hirai $S$, Toguchi H. In vitro and in vivo evaluation of mucoadhesive microspheres prepared for the gastrointestinal tract using polyglycerol esters of fatty acids and a poly (acrylic acid) derivative. Pharm. Res. 1995; 12: 397-405.

9. Groning R, Berntgen M, Georgarakis M. Acyclovir serum concentrations following peroral administration of magnetic depot tablets and the influence of extracorporeal magnets to control gastrointestinal transit. Eur. J. Pharm. Biopharm. 1998; 46: 285-291.
10. Fix JA, Cargill R, Engle $K$. Controlled gastric emptying: Part 3. Gastric residence time of a nondisintegrating geometric shape in human volunteers. Pharm. Res. 1993; 10: 1087-1089.

11. Park K. Enzyme-digestible swelling hydrogels as platforms for long-term oral drug delivery: synthesis and characterization. Biomaterials 1988; 9: 435-441.

12. Kawashima $Y$, Niwa $T$, Takeuchi $H$, Hino $T$, Itoh $Y$. Hollow microspheres for use as a floating controlled drug delivery system in the stomach. J. Pharm. Sci. 1992; 81: 135-140.

13. Whitehead L, Fella JT, Colletta JH, Sharma HL, Smith AM. Floating dosage forms: an in vivo study demonstrating prolonged gastric retention. J. Control Release 1998; 55: 3-12.

14. Yadav A, Jain DK. In-vitro characterization of gastroretentive microballoons prepared by the emulsion solvent diffusion method. J. Adv. Phar. Tech. Res. 2010; 1: 56-67.

15. Streubel A, Siepmann J, Bodmeier R. Multiple unit gastroretentive drug delivery systems: a new preparation method for low density microparticles. J. Microencapsul. 2003; 20: 329-347.

16. The Indian Pharmacopoeia 2007, Vol-II, Indian Pharmacopoeia Commission, Ghaziabad, pp 740-742.

17. Costa P, Lobo JMS. Modeling and comparison of dissolution profiles. Eur. J. Pharm. Sci. 2001; 13: 123-133.

18. Wagner JG. Interpretation of percent dissolved-time plots derived from testing of conventional tablets and capsules. J. Pharm. Sci. 1969; 58: 1253-1257.

19. Schefter E, Higuchi T. Dissolution behavior of crystalline solvated and non-solvated forms of some pharmaceuticals. J. Pharm. Sci. 1963; 52: 781-791.

20. Kawashima Y, Iwamoto $T$, Niwa $T$, Takeuchi $H$, Hino $T$. Role of the solvent diffusion rate modifier in a new emulsion solvent diffusion method for preparation of ketoprofen microspheres. J. Microencapsul. 1993; 10: 329-340. 